Full Length Article

\title{
Acetone-butanol-ethanol (ABE) fermentation of soluble and hydrolyzed sugars in apple pomace by Clostridium beijerinckii P260
}

\author{
Qing Jin ${ }^{\mathrm{a}}$, Nasib Qureshi ${ }^{\mathrm{b}}$, Hengjian Wang ${ }^{\mathrm{a}}$, Haibo Huang, ${ }^{\mathrm{a}, *}$ \\ ${ }^{a}$ Department of Food Science and Technology, Virginia Polytechnic Institute and State University, 1230 Washington St. SW, Blacksburg, VA 24061, USA \\ ${ }^{\mathrm{b}}$ United States Department of Agriculture (USDA), ARS, National Center for Agricultural Utilization Research (NCAUR), Bioenergy Research Unit, 1815 N University \\ Street, Peoria, IL 61604, USA
}

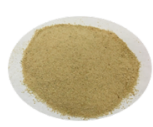

Apple Pomace $(1 \mathrm{~kg}, \mathrm{DW})$

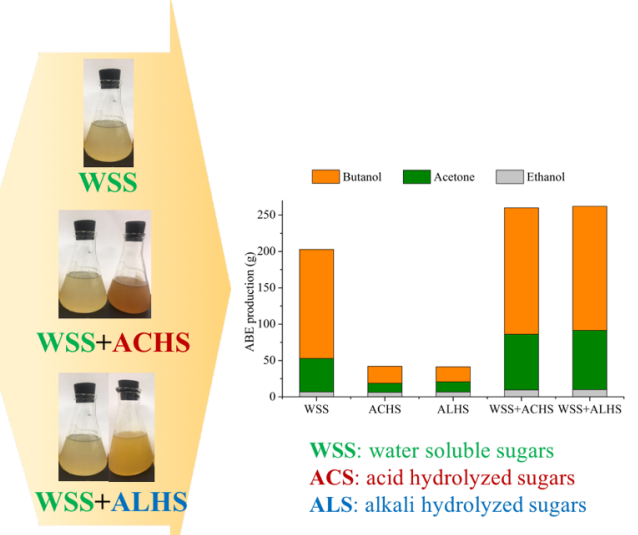

A R T I C L E I N F O

\section{Keywords:}

Acetone-butanol-ethanol (ABE)

Fermentation

Food waste

Sulfuric acid pretreatment

Sodium hydroxide pretreatment

\begin{abstract}
A B S T R A C T
The decreasing supply of fossil fuels and increasing environmental concern of food waste disposal have raised interests in food waste conversation to biofuels such as butanol. Apple pomace, a food processing waste rich in carbohydrates, is a good feedstock for butanol production. The goal of this study is to present and evaluate a process to thoroughly convert apple pomace water soluble sugars (WSS) and hydrolyzed sugars from structural carbohydrates to acetone-butanol-ethanol (ABE) by fermentation. WSS was extracted from apple pomace by hot water. The solid residue was pretreated with acid or alkali followed by enzymatic hydrolysis to obtain acid hydrolyzed sugars (ACHS) or alkali hydrolyzed sugars (ALHS). Finally, WSS, ACHS, ALHS, WSS + ACHS, and WSS + ALHS were used as substrates to produce ABE by Clostridium beijerinckii P260, respectively. Acid and alkali pretreated apple pomace showed significantly $(p<0.05)$ higher glucose yield after cellulase hydrolysis compared with that of unpretreated apple pomace. Addition of pectinase increased hydrolyzed glucose yield by $27.9 \%, 26.9 \%$, and $33.0 \%$ for acid pretreated sample, alkali pretreated sample, and unpretreated sample, respectively. Fermentation results revealed that inhibitors generated during pretreatment could negatively affect
\end{abstract}

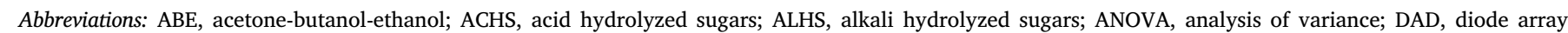

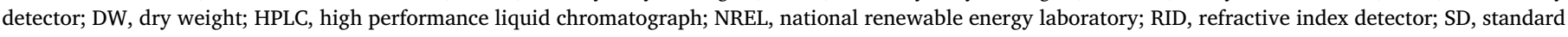
deviation; WSS, water soluble sugars

* Corresponding author at: Human \& Agricultural Biosciences Bldg. 1, Room 402J, 1230 Washington St. SW, Blacksburg, VA 24061, USA.

E-mail addresses: jin622@vt.edu (Q. Jin), Nasib.Qureshi@ars.usda.gov (N. Qureshi), hewang@vt.edu (H. Wang), huang151@vt.edu (H. Huang). 
the ABE fermentation rate and titers; however, this negative effect could be alleviated by mixing the hydrolyzed sugars with water soluble sugars. A total of 202.8, 42.1, 41.4, 260.1, and 262.2 $\mathrm{g}$ of ABE was produced from each $\mathrm{kg}$ of dry apple pomace using WSS, ACHS, ALHS, WSS + ACHS, and WSS + ALHS as the substrates, respectively, based on the mass balance.

\section{Introduction}

Apple (the Rosaceae family, genus Malus), as one of the most widely cultivated fruits, has an increasing production over the past ten years, reaching more than 70 million metric tons production in 2015 [1,2]. About $30 \%$ of apples are industrially processed to produce juice, cider, or puree which generate large amounts of pulp, skin, and seed wastes, called pomace. Apple pomace occupies around $25-30 \%$ of the original fruits in dry mass [3]. As the industrial byproduct, it contains valuable compounds such as soluble sugars, structural carbohydrates (e.g., cellulose and hemicellulose), minerals, and vitamins. However, due to its low protein content, apple pomace has low nutritional value as animal feed, and most apple pomace ends up in landfills [1]. The high acidity and seed anti-germination activity of apple pomace pose a potential threat to the soil. In addition, the high soluble sugars in apple pomace can be fermented in rumen causing alcoholaemia which intoxicates the animals [4]. Since apple pomace is abundantly available and contains compounds that can be valorized, it calls for a shift from simple pomace waste pollution control to a more holistic approach, that is, apple pomace as the valuable resource can be sustainably processed to valueadded chemicals and biofuels [5].

Recently, apple pomace has been used to produce organic acids, antioxidants, enzymes, ethanol, biogas, and butanol $[4,6]$. Among the aforementioned biomolecules, butanol is a particularly promising product due to its several advantages: 1 ) butanol occupies a current market over $\$ 6$ billion each year, which is expected to reach $\$ 18$ billion by 2020 due to the increasing need for bio-based chemicals [7]; 2) butanol serves as an excellent sustainable biofuel alternative to ethanol. The energy content in butanol is $30 \%$ higher than ethanol and is closer to gasoline; moreover, it has lower vapor pressure and is less flammable, making it compatible with gasoline in various proportions [8]; 3) butanol is an important industrial intermediate chemical which can be used to generate other products such as acrylic esters, butyl acetate, and glycol ethers [9].

Currently, butanol is industrially produced from petroleum or fermentation of corn and cassava. Due to the rising food price, food wastes such as wheat straw, rice straw, barley straw, corn stover, and corn cob have been studied as substrates for butanol production through acetone-butanol-ethanol (ABE) fermentation by Clostridium beijerinckii, or C. acetobutylicum, etc [10]. Our previous research also showed the advantages of using food waste to produce biofuels [11]. Apple pomace, as agricultural solid waste, is abundantly available and rich in soluble sugars and structural carbohydrates, making it a good candidate for butanol production. The relevant research using apple pomace as the feedstock for ABE fermentation is limited. A published study used the soluble sugars in apple pomace to produce butanol [12]. Recently, researchers applied different pretreatments (autohydrolysis, acids, alkali, organic solvent, and surfactant) followed by enzymatic hydrolysis to break down the structural carbohydrates of apple pomace into hydrolyzed sugars, which were further fermented to butanol [13]. Although separate studies on soluble sugars or structural carbohydrates utilization exist, no research has been conducted to evaluate the technical feasibility of comprehensive utilization of all (both soluble and insoluble) carbohydrates in apple pomace to obtain butanol. The thorough utilization of carbohydrates in apple pomace will not only maximize the butanol production but also minimize the residual waste after processing.

Therefore, the objective of this study is to develop a process to make a full utilization of the carbohydrates (both soluble and structural sugars) in apple pomace to maximize butanol production. Apple pomace was extracted by hot water to obtain soluble sugars at first. The solid residue, which is rich in lignocellulose, was then pretreated with dilute acid or alkali solution followed by enzymatic hydrolysis to get hydrolyzed sugars. Pretreatment and enzymatic hydrolysis parameters were optimized in these steps. Finally, soluble sugars and acid/alkali hydrolyzed sugars were combined as the substrate for butanol production by C. beijerinckii P260.

\section{Materials and methods}

\subsection{Chemicals and materials}

Sulfuric acid, sodium hydroxide, acetone, butanol, ethanol, acetic acid, and butyric acid were purchased from Fisher Scientific (Fair Lawn, NJ, USA). Glucose, xylose, arabinose, fructose, sucrose, galactose, furfural, and HMF were obtained from Sigma-Aldrich (St. Louis, MO, USA). Cooked meat medium was obtained from Difco ${ }^{\mathrm{TM}}$ (Becton, Dickinson and Company, Sparks, MD, USA). Yeast extract was purchased from Bacto-Dickinson \& Co. (Sparks, MD, USA). C. beijerincki P260 spores were maintained in sterile distilled water at $4{ }^{\circ} \mathrm{C}$ until utilization. The enzymes including cellulase (Cellic CTec2, 132 FPU/ $\mathrm{mL}$ ) and pectinase (Pectinex ${ }^{\circledast}$ Ultra SPL, $4186 \mathrm{EU} / \mathrm{mL}$ ) were supplied by

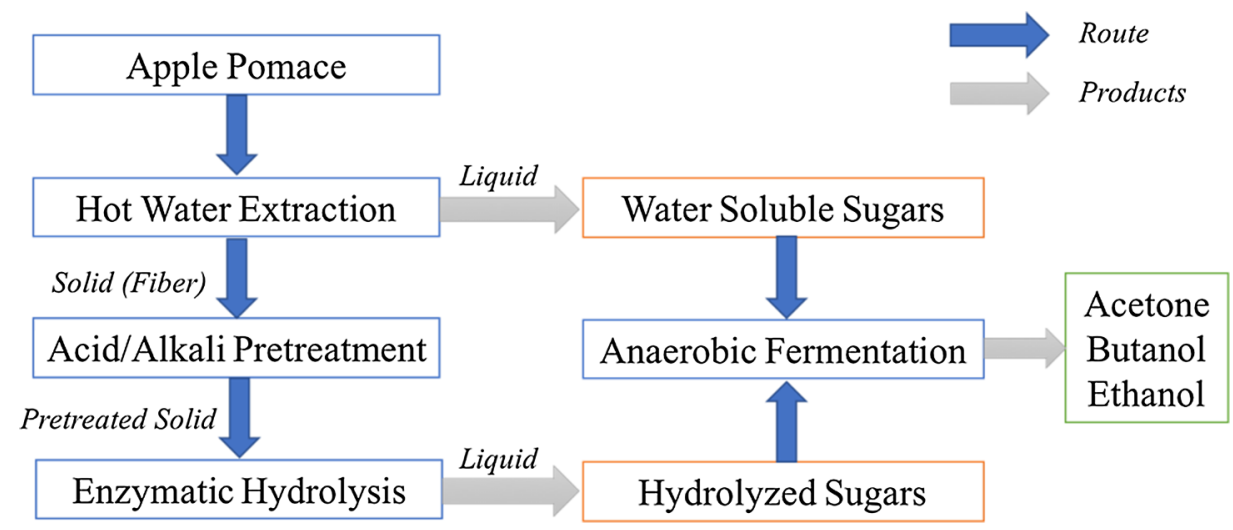

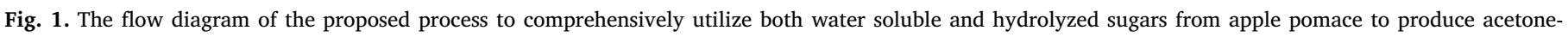
butanol-ethanol (ABE). 
Novozymes North America Inc. (Franklinton, NC, USA).

Apple pomace (Golden Delicious, $3 \mathrm{~kg}$ ) was obtained from the pilotscale food processing plant of Virginia Tech (Blacksburg, VA 24061) in October 2016. After filter press to extract juice, the leftover pomace was collected and stored at $-20^{\circ} \mathrm{C}$ until utilization. Apple pomace was dried (moisture content $7.3 \%$ ) and milled with a laboratory hammer mill to a particle size of less than $0.85 \mathrm{~mm}$, and then stored at $-20^{\circ} \mathrm{C}$ until further utilization.

\subsection{Soluble sugars extraction}

Fig. 1 illustrates the flow diagram of the proposed process. The hot water extraction of apple pomace was applied to obtain residual soluble sugars in apple pomace. In details, apple pomace powder $(15 \mathrm{~g})$ was subjected to deionized water $(300 \mathrm{~mL})$ extraction in the autoclave at $121^{\circ} \mathrm{C}$ for $30 \mathrm{~min}[14,15]$. The autoclaved mixture was centrifuged $\left(16,639 \times g, 10 \mathrm{~min}, 4^{\circ} \mathrm{C}\right)$ to separate solid and supernatant. The supernatant was determined for sugar composition and concentration using high performance liquid chromatograph (HPLC) as described later. The solid was collected and subjected to sequential pretreatment and enzymatic hydrolysis to obtain hydrolyzed sugars. The sugar extraction was conducted in triplicate.

\subsection{Acid and alkali pretreatments}

The apple pomace solid residue (with $4.0 \%$ of pectin, dry weight, DW) was pretreated by dilute sulfuric acid or sodium hydroxide. Varied concentrations of sulfuric acid ( 1 and $2 \%, v / v)$ or sodium hydroxide ( 1 and $2 \%, \mathrm{w} / \mathrm{v}$ ) with a solid to liquid ratio of $1: 20$ for different pretreatment times ( 30 and $60 \mathrm{~min}$ ) at $121^{\circ} \mathrm{C}$ were evaluated to identify the best pretreatment conditions. After pretreatment, the solid was separated from the liquid by centrifugation $\left(16,639 \times g, 10 \mathrm{~min}, 4^{\circ} \mathrm{C}\right)$. The solid residue was then washed with deionized water five times to remove most of residual sulfuric acid or sodium hydroxide and potential inhibitors generated during pretreatment. Each pretreatment was performed in triplicate.

\subsection{Enzymatic hydrolysis}

Enzymatic saccharification of unpretreated apple pomace solid residue (moisture content of $86.6 \%$ ), acid pretreated apple pomace solid residue (moisture content of $88.9 \%$ ), and alkali pretreated apple pomace solid residue (moisture content of $89.7 \%$ ) was performed with $13 \mathrm{FPU} / \mathrm{g}$ dry biomass of cellulase addition. Two solid loadings including 2.5 and $5 \%$ were selected herein due to the high viscosity of the pretreated samples. The $\mathrm{pH}$ of the samples was adjusted to 5.0 using $0.1 \mathrm{M}$ sodium citrate buffer. The saccharification was conducted in a shaking water bath $\left(50^{\circ} \mathrm{C}\right)$ at $120 \mathrm{rpm}$ for $72 \mathrm{~h}$. After selecting one best acid pretreatment and one best alkali pretreatment, $183 \mathrm{EU} / \mathrm{g}$ dry biomass of pectinase was added to test the synergistic action of cellulase and pectinase in releasing sugars from apple pomace. Pectin (approximate $0.1 \%$ in apple pomace after both acid and alkali pretreatments) matrix may act as a barrier for the enzymatic hydrolysis of cellulose. Thus, the degradation of pectin by pectinase may help sugar release from cellulose. The selection of cellulase and pectinase loadings was based on the manufacturer's guidelines and previous studies $[3,16]$. During the enzymatic hydrolysis, samples $(1 \mathrm{~mL})$ were collected at different times $(0,6,12,24,48,72 \mathrm{~h})$, and then centrifuged $(16,639 \times \mathrm{g}$, $10 \mathrm{~min}, 4^{\circ} \mathrm{C}$ ) to collect supernatant for further sugar analysis. Enzymatic hydrolysis was performed in triplicate.

\subsection{Acetone-butanol-ethanol (ABE) fermentation}

C. beijerinckii P260 spores $(100 \mu \mathrm{L})$ were heat shocked at $80^{\circ} \mathrm{C}$ for $2 \mathrm{~min}$ for activation. The heat shocked spore solution $(20 \mu \mathrm{L})$ was then transferred to the cooked meat medium ( $3.5 \mathrm{~g}$ cooked meat, $0.6 \mathrm{~g}$ glucose, and $35 \mathrm{~mL}$ distilled water). The medium was previously autoclaved at $121^{\circ} \mathrm{C}$ for $15 \mathrm{~min}$ followed by cooling down to room temperature. After spore inoculation, the medium was incubated at an anaerobic environment $\left(35^{\circ} \mathrm{C}\right)$ for $16-18 \mathrm{~h}$, and the culture was used as the first-stage inoculum. Following that, $7-8 \mathrm{~mL}$ of the first-stage culture was transferred to the $\mathrm{P} 2$ medium. The medium containing carbon source and yeast extract was autoclaved at $121^{\circ} \mathrm{C}$ for $15 \mathrm{~min}$ followed by cooling to $35^{\circ} \mathrm{C}$, and then, filter-sterilized P2 stock solutions [(buffer: $\mathrm{KH}_{2} \mathrm{PO}_{4}, 50 \mathrm{~g} / \mathrm{L} ; \mathrm{K}_{2} \mathrm{HPO}_{4}, 50 \mathrm{~g} / \mathrm{L}$; ammonium acetate, $220 \mathrm{~g}$ / $\mathrm{L}$ ), (vitamin: para-amino-benzoic acid, $0.1 \mathrm{~g} / \mathrm{L}$; thiamin, $0.1 \mathrm{~g} / \mathrm{L}$; biotin, $0.001 \mathrm{~g} / \mathrm{L}$ ), and (mineral: $\mathrm{MgSO}_{4} \cdot 7 \mathrm{H}_{2} \mathrm{O}, 20 \mathrm{~g} / \mathrm{L} ; \mathrm{MnSO}_{4} \cdot \mathrm{H}_{2} \mathrm{O}, 1 \mathrm{~g} / \mathrm{L}$; $\left.\left.\mathrm{FeSO}_{4} \cdot 7 \mathrm{H}_{2} \mathrm{O}, 1 \mathrm{~g} / \mathrm{L} ; \mathrm{NaCl}, 1 \mathrm{~g} / \mathrm{L}\right)\right]$ were aseptically added $(1 \mathrm{~mL} /$ each) [17]. The P2 medium culture was allowed to grow for $7-8 \mathrm{~h}$ at $35^{\circ} \mathrm{C}$ anaerobically, after which it was ready to be inoculated into the $\mathrm{ABE}$ fermentation medium.

Five media including water soluble sugar (WSS), acid hydrolyzed sugars (ACHS), alkali hydrolyzed sugars (ALHS), WSS combined with ACHS, and WSS combined with ALHS were used as ABE fermentation substrates, respectively. ABE fermentation with pure glucose as a substrate was also conducted for a control purpose. The ABE fermentation was conducted in $50 \mathrm{~mL}$ centrifuge tubes $(20 \mathrm{~mL}$ substrates). Before inoculation, all substrates were amended with $2 \mathrm{~g} / \mathrm{L}$ yeast extract and sterilized at $121^{\circ} \mathrm{C}$ for $15 \mathrm{~min}$ followed by adding $1 \mathrm{~mL}$ of each filtersterilized stock solution including vitamins, buffer, and minerals [17]. Then, $1.5 \mathrm{~mL}$ of actively growing cells developed in P2 medium were added to different substrates. The fermentation was conducted anaerobically at $35^{\circ} \mathrm{C}$. ABE fermentation was performed in duplicate. ABE yield and productivity were calculated to evaluate the fermentation efficiency:

$\mathrm{ABE}$ yield $=\frac{\mathrm{g} / \mathrm{L} \text { of Total } \mathrm{ABE}}{\mathrm{g} / \mathrm{L} \text { of Total sugar utilized }}$

$\operatorname{ABE}$ productivity $(\mathrm{g} / \mathrm{L} / \mathrm{h})=\frac{\mathrm{g} / \mathrm{L} \text { of Total } \mathrm{ABE}}{\mathrm{h} \text { of Fermentation time }}$

\subsection{Analytical methods}

For the soluble sugars determination, apple pomace $(1 \mathrm{~g})$ was extracted by $85 \%$ ethanol $(50 \mathrm{~mL})$ for 30 min with constant shaking in a water bath at $50{ }^{\circ} \mathrm{C}$. The extraction procedure was repeated twice. The extracted liquid was combined and vacuum evaporated at $50^{\circ} \mathrm{C}$ to remove ethanol, and the residue was re-suspended in ultrapure water (obtained from Thermo Scientific $^{\mathrm{TM}}$ Barnstead $^{\mathrm{TM}}$ MicroPure $^{\mathrm{TM}}$ Water Purification System, 18.2 M $\Omega$ cm, Fisher Scientific, Fair Lawn, NJ, USA) for sugars determination [18]. Structural carbohydrates including glucan, xylan, arabinan, galactan, and mannan, lignin, and extractives of apple pomace were analyzed according to the National Renewable Energy Laboratory (NREL) procedures [19-22]. Pectin was determined by the hot acid extraction method [23]. To be specific, $5 \mathrm{~g}$ of samples were mixed with $250 \mathrm{~mL}$ distilled water (adjusting $\mathrm{pH}$ to 2.5 with citric acid), and the mixture was incubated in the water bath $\left(95^{\circ} \mathrm{C}\right)$ for $30 \mathrm{~min}$. After that, the mixture was filtered (Whatman \#1 filter paper) and the filtrate was cooled overnight at $4{ }^{\circ} \mathrm{C}$. Then, $125 \mathrm{~mL}$ of $96 \%$ ethanol was added to the cold filtrate. After stirring for $10 \mathrm{~min}$, the liquid was left overnight to precipitate pectin. Finally, the precipitate was filtered (Whatman \#1 filter paper) and dried in the oven $\left(55^{\circ} \mathrm{C}\right)$ for $24 \mathrm{~h}$. The pectin content was determined gravimetrically.

Sugars (glucose, sucrose, xylose, fructose, galactose, arabinose, and mannose) were determined by Agilent 1200 HPLC system (Agilent Technologies, Santa Clara, CA, USA) with a refractive index detector (RID). Samples were filtered through $0.2 \mu \mathrm{m}$ syringe filter (Waters Corporation, Milford, MA, USA) before analyzing by HPLC. A Bio-Rad Aminex HPX-87P column (Bio-Rad Laboratories, Hercules, CA, USA) was used with ultrapure water as the mobile phase (flow rate of $0.6 \mathrm{~mL}$ / min) at $80^{\circ} \mathrm{C}$. The total running time was $30 \mathrm{~min}$, and the injection 
Table 1

Chemical composition of apple pomace after hot water extraction.

\begin{tabular}{ll}
\hline Components & Content (\%, DW) \\
\hline Extractives & $29.7 \pm 1.6$ \\
Structural carbohydrates & \\
$\quad$ Glucan & $34.9 \pm 1.1$ \\
Xylan & $7.2 \pm 0.5$ \\
Arabinan & $4.7 \pm 0.5$ \\
Galactan & $5.9 \pm 0.5$ \\
Lignin & \\
Acid soluble lignin & $2.4 \pm 0.2$ \\
Acid insoluble lignin & $12.4 \pm 0.1$ \\
\hline
\end{tabular}

Data are expressed as mean $\pm \mathrm{SD}$.

volume was $20 \mu \mathrm{L}$.

Total phenolic compounds were measured by the Folin-Ciocalteu method [24]. To be specific, liquid sample $(0.5 \mathrm{~mL})$ was mixed with Folin-Ciocalteau reagent $(0.2 \mathrm{~N}, 2.5 \mathrm{~mL})$ and saturated sodium carbonate $(7.5 \%, \mathrm{w} / \mathrm{v}, 2 \mathrm{~mL})$. The mixture was incubated at room temperature for $2 \mathrm{~h}$ and then measured the absorbance at $765 \mathrm{~nm}$ by the Genesys $^{\mathrm{TM}}$ 10S UV/VIS spectrophotometer (Thermo Fisher Scientific, Madison, WI, USA). Gallic acid was used as the standard.

Fermentation products including acetone, butanol, ethanol, acetic acid, and butyric acid and degradation products including acetic acid, HMF, and furfural were measured by Agilent 1200 HPLC system (Agilent Technologies) with a 1260 RID and a 1200 diode array detector (DAD). Samples were centrifuged at $15,871 \times g$ for $5 \mathrm{~min}$, and then filtered through $0.2 \mu \mathrm{m}$ syringe filter (Waters Corporation) prior to analyses. A Bio-Rad Aminex HPX-87H column $\left(50^{\circ} \mathrm{C}\right)$ were used for fermentation products separation. Sulfuric acid $(5 \mathrm{mM})$ solution was used as mobile phase. Acetic acid, ethanol, and butanol were detected with the RID, and other chemicals were detected by the DAD with different wavelengths (butyric acid, $210 \mathrm{~nm}$; acetone, $265 \mathrm{~nm}$; HMF and furfural, $280 \mathrm{~nm}$ ). The flow rate was set at $0.6 \mathrm{~mL} / \mathrm{min}$ with the injection volume of $5 \mu \mathrm{L}$.

\subsection{Statistical analysis}

Comparisons among treatments were analyzed by analysis of variance (ANOVA) according to Tukey's test using SPSS software (Version 19.0, SPSS Inc., Chicago, IL, USA). Differences were considered significant when $p<0.05$.

\section{Results and discussion}

\subsection{Water soluble sugars extraction}

The composition of apple pomace is affected by numerous factors such as variety, ripen stage, physical and chemical properties of the apples, juice extraction technologies, various enzyme utilization during extraction, and with or without press aid such as rice hulls [25]. The variability in the composition of apple pomace will affect the process design. For example, the contents of soluble sugars such as sucrose (from 1.4 to $11.2 \%$, DW) [26,27], fructose (from 13.6 to $35.0 \%$, DW) $[12,28]$, and glucose (from 6.1 to $50.8 \%$, DW) in different apple pomaces may determine if recovery of those soluble sugars is needed $[28,29]$. In addition, the variation in soluble and insoluble fibers in apple pomace may affect the selection of pretreatment methods and enzymes to obtain hydrolyzed sugars. A detailed discussion about selection pretreatment methods and enzymes is addressed in later sections.

In the present study, the composition analysis showed that the major soluble sugars extracted by $85 \%$ ethanol in apple pomace included fructose (27.2\%, DW), sucrose (16.3\%, DW), and glucose $(8.0 \%$, DW); minor amounts of xylose $(0.2 \%$, DW), galactose $(0.3 \%$, DW), and arabinose $(0.1 \%$, DW) were also detected. The high content of soluble sugars remained in apple pomace might be due to the incomplete pressing of ground apples when producing juice [3].

Due to the high amount of soluble sugars existed in the apple

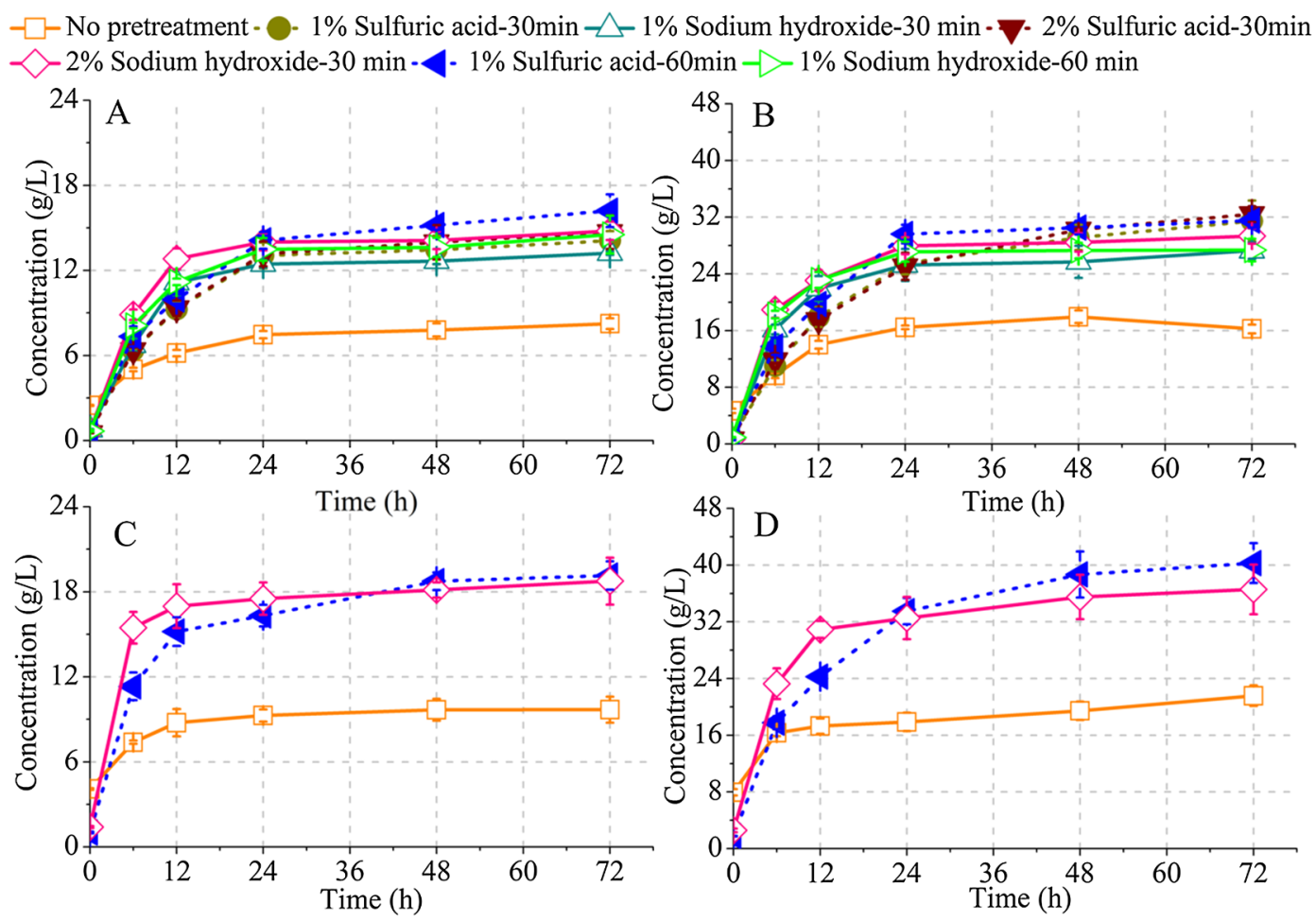

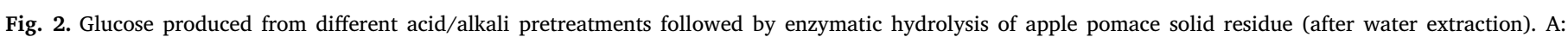

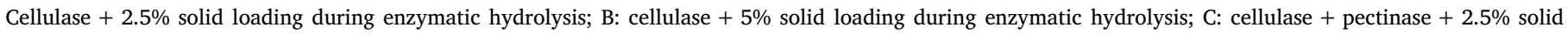
loading during enzymatic hydrolysis; D: cellulase + pectinase $+5 \%$ solid loading during enzymatic hydrolysis. The error bars represent SD. 
pomace, the first step we applied herein was using hot water to extract those sugars for further fermentation utilization. As a result, the extracted solution contained a total of $28.3 \mathrm{~g} / \mathrm{L}$ of sugars. Among them, fructose $(14.7 \mathrm{~g} / \mathrm{L})$ was the major sugar, followed by sucrose $(8.2 \mathrm{~g} / \mathrm{L})$ and glucose $(5.1 \mathrm{~g} / \mathrm{L})$. Small amounts of other sugars (less than $0.3 \mathrm{~g} / \mathrm{L}$ ) were also extracted. The soluble sugar enriched liquid was used as the substrate for subsequent ABE fermentation.

\subsection{Hydrolyzed sugars production}

After hot water extraction, there was $29.7 \%$ of extractives (mainly ethanol soluble fats and waxes, soluble dietary fiber, and some minerals) left in the solid residue. The extractives might be recovered for nonpolar compounds extraction. In the present study, the extractives were removed by acid or alkali pretreatment and following washing steps. Besides extractives, the solid residue was rich in cell wall materials such as lignin and structural carbohydrates (Table 1). A total of $14.8 \%$ (DW) lignin was found in the solid residue. As to the structural carbohydrates, glucan was the major one $(34.9 \%$, DW), the total contents of other structural carbohydrates (hemicellulose components including xylan, arabinan, and galactan) were $17.8 \%$ (DW).

Lignin, some crosslinks between lignin and structural carbohydrates such as xylan, and some fibers such as pectin serve as physical barriers to reduce the accessibility for enzymatic saccharification of the structural carbohydrates [30]. Therefore, a pretreatment process was performed to disrupt the recalcitrant structure of biomass and make the structural carbohydrates more accessible by enzymes. In the present study, acid (sulfuric acid) and alkali (sodium hydroxide) pretreatments, the two of the most effective pretreatments to reduce biomass recalcitrance, with different concentrations (1 and $2 \%$ ) and pretreatment times (30 and $60 \mathrm{~min}$ ) were tested. In addition, structural carbohydrates could not be directly fermented by $C$. beijerinckii P260. Therefore, after pretreatment, enzymatic hydrolysis is needed to break the structural carbohydrates to fermentable (hydrolyzed) sugars. In this study, cellulase with or without pectinase addition was applied in the enzymatic hydrolysis step, during which two solid loadings (2.5 and $5 \%, \mathrm{w} / \mathrm{v}$ ) were conducted.

The aim of evaluating these parameters was to identify the best operating conditions to get the maximum hydrolyzed sugars for the subsequent $\mathrm{ABE}$ fermentation. Glucose was selected as the optimization target. Other hydrolyzed sugars such as xylose, arabinose, and galactose were not reported herein due to their negligible concentrations in hydrolysates. As could be seen in Fig. 2A, both the acid and alkali pretreatments of apple pomace improved the glucose production at $2.5 \%$ solid loading compared with the unpretreated sample. After $72 \mathrm{~h}$ of cellulase hydrolysis, the maximum 16.2 and $14.8 \mathrm{~g} / \mathrm{L}$ of glucose were obtained from acid ( $1 \%$ sulfuric acid for $60 \mathrm{~min}$ ) and alkali ( $2 \%$ sodium hydroxide for $30 \mathrm{~min}$ ) pretreatments, respectively, while the glucose production from unpretreated apple pomace solid residue was significantly $(p<0.05$ ) lower, only $8.2 \mathrm{~g} / \mathrm{L}$. When hydrolysis was conducted at $5 \%$ solid loading, the maximum glucose concentration doubled to 32.4 and $29.3 \mathrm{~g} / \mathrm{L}$ for acid ( $2 \%$ sulfuric acid for $30 \mathrm{~min}$ ) and alkali ( $2 \%$ sodium hydroxide for $30 \mathrm{~min}$ ) pretreatments, respectively (Fig. 2B). The glucose concentration in the unpretreated pomace sample (at $5 \%$ solid loading) was $16.2 \mathrm{~g} / \mathrm{L}$.

One of the factors that affecting pretreatment efficiency is the composition of the apple pomace. Acid pretreatment is mainly aimed to break down hemicellulose such as xylan in biomass and make cellulose more accessible to enzymes during enzymatic hydrolysis [30]. This pretreatment method has been studied on different biomass and is more favorable in the industrial application [30]. However, some degradation products such as furfural, HMF, acetic acid, and phenolic compounds may be generated during the pretreatment process, which may affect the metabolism of microorganism in the fermentation [31]. Alkali pretreatment is effective on removing lignin and acetyl groups to increase the cellulose digestibility during enzymatic hydrolysis [30]. Compared with acid pretreatment, less structural carbohydrates such as cellulose and hemicellulose are solubilized during alkali pretreatment

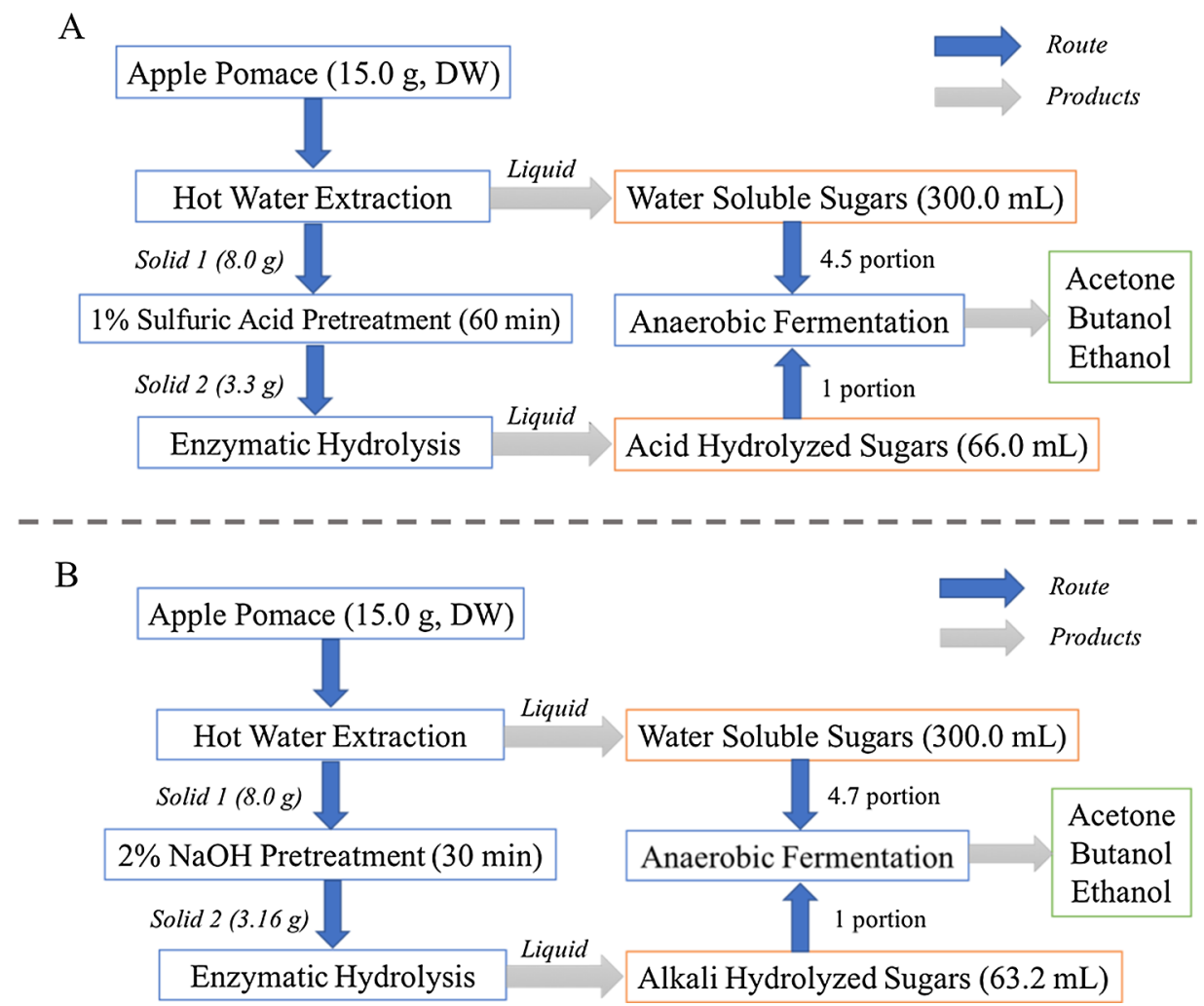

Fig. 3. Water soluble sugars (WSS) combined with acid or alkali hydrolyzed sugars (ACHS or ALHS) for acetone-butanol-ethanol (ABE) fermentation. A: WSS + ACHS; B: WSS + ALHS. 
[31]. However, the efficiency of alkali pretreatment is highly dependent on the lignin content of the biomass [30]. Therefore, the selection of pretreatment method should be based on the composition due to the content variation of the lignin (from 6.4 to $20.4 \%$, DW) and hemicellulose (from 4.1 to $24.4 \%$, DW) in apple pomaces $[4,25,27]$. As in the present study, the apple pomace residue contained $14.8 \%$ (DW) of lignin and $17.8 \%$ (DW) of hemicellulose. Although no significant $(p>0.05)$ difference was found within different acid or alkali pretreatments, the acid pretreatment groups had a higher glucose production compared with the alkali pretreatment groups on average. A similar result was found in a previous study that alkali (sodium hydroxide and potassium hydroxide) was not as effective as acids (sulfuric acid, hydrogen chloride, and nitric acid) to pretreat apple pomace for the production of hydrolyzed sugars [13].

We further investigated the synergistic cooperation of cellulase and pectinase for the glucose production during hydrolysis. In this experiment, acid ( $1 \%$ sulfuric acid for $60 \mathrm{~min}$ ) and alkali ( $2 \%$ sodium hydroxide for $30 \mathrm{~min}$ ) pretreatments were selected due to their optimal performance as shown in Fig. 2A and B. As could be seen in Fig. 2C, by addition of pectinase, the glucose yield increased by $17.5 \%, 18.1 \%$, and $26.9 \%$ for unpretreated, sulfuric acid pretreated, and sodium hydroxide pretreated samples at $2.5 \%$ solid loading, respectively. At $5 \%$ of solid loading, the maximum of 40.3 and $36.6 \mathrm{~g} / \mathrm{L}$ glucose could be obtained after sulfuric acid and sodium hydroxide pretreatments followed by enzymatic (cellulase and pectinase) hydrolysis, respectively (Fig. 2D). The glucose yield increased by $33.0 \%$ for the unpretreated sample, $27.9 \%$ for the sulfuric acid pretreated sample, and $26.9 \%$ for the sodium hydroxide pretreated sample. Studies have shown that the cell wall of apple pomace contained a pectin matrix, which could block cellulose, leading to inefficient enzymatic digestibility [16]. Therefore, breaking down pectin network using pectinase could facilitate enzymatic attachment to cellulose, consequently releasing more glucose.

\subsection{ABE production}

Five types of sugar including WSS, ACHS, ALHS, WSS + ACHS, and WSS + ALHS obtained before were used as the substrates for the ABE fermentation, respectively. The liquid to liquid ratios of WSS to ACHS (4.5:1) and WSS to ALHS (4.7:1) were calculated based on the mass balance of the designed process (Fig. 3). To be specific, after hot water extraction, $300 \mathrm{~mL}$ WSS and $8 \mathrm{~g}$ fiber enriched solid residue could be obtained from $15 \mathrm{~g}$ dry apple pomace. The solid residue was then pretreated by sulfuric acid or sodium hydroxide to get $3.3 \mathrm{~g}$ or $3.16 \mathrm{~g}$ pretreated solid residue, respectively. After that, the acid and alkali pretreated solid residues were enzymatically hydrolyzed, obtaining $66.0 \mathrm{~mL}$ of ACHS and $63.2 \mathrm{~mL}$ of ALHS, respectively. Therefore, for 1

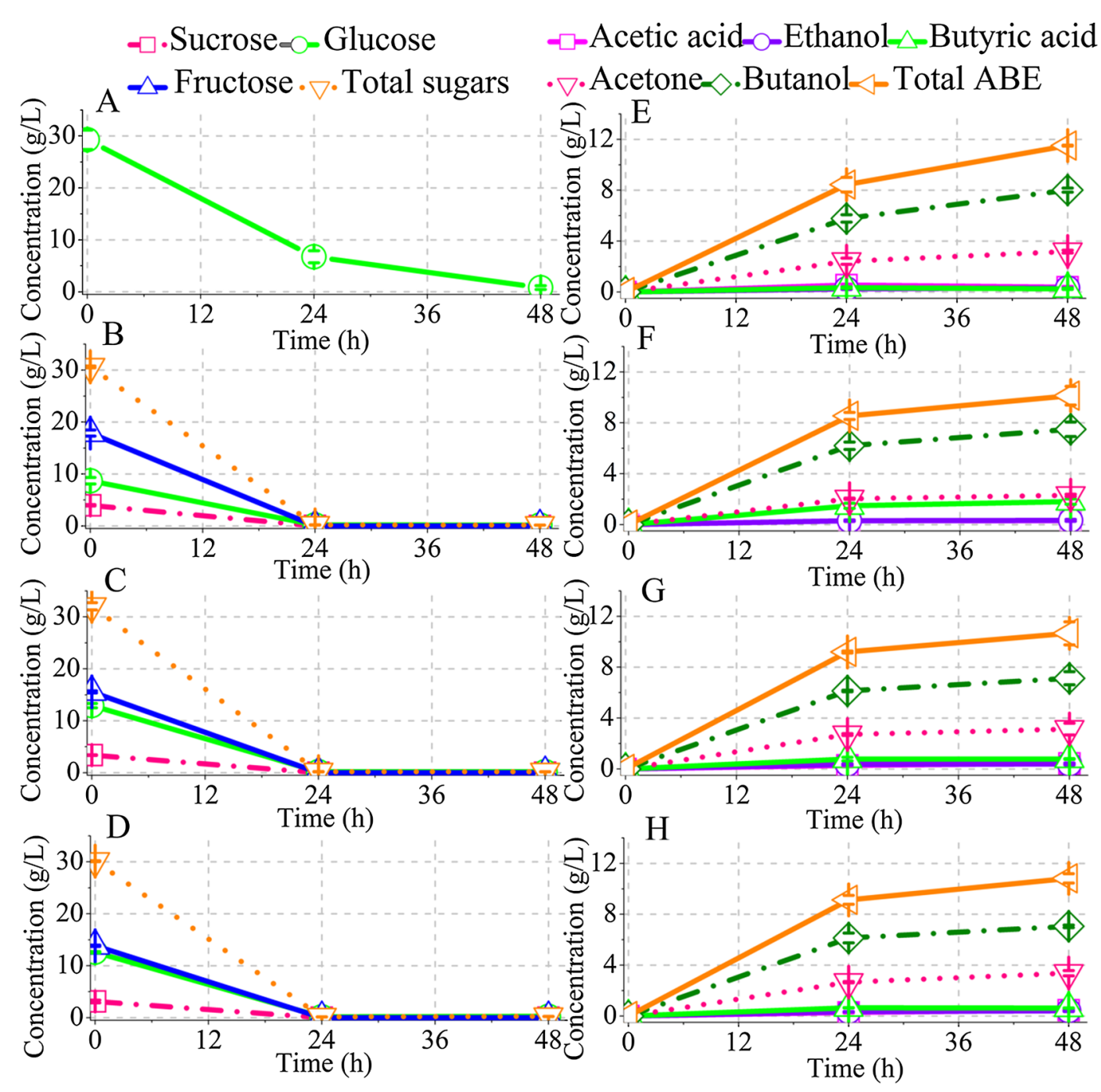

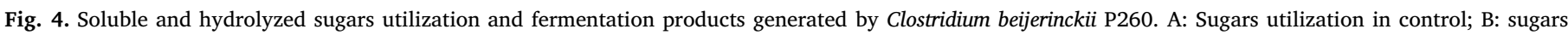

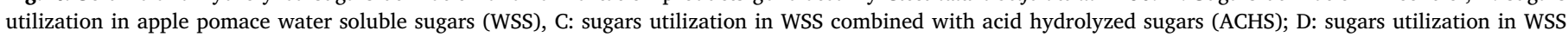

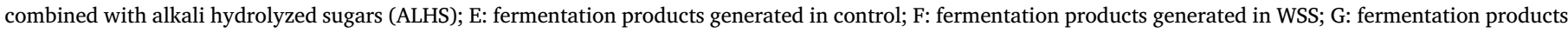
generated in WSS + ACHS; H: fermentation products generated in WSS + ALHS. The error bars represent SD. 


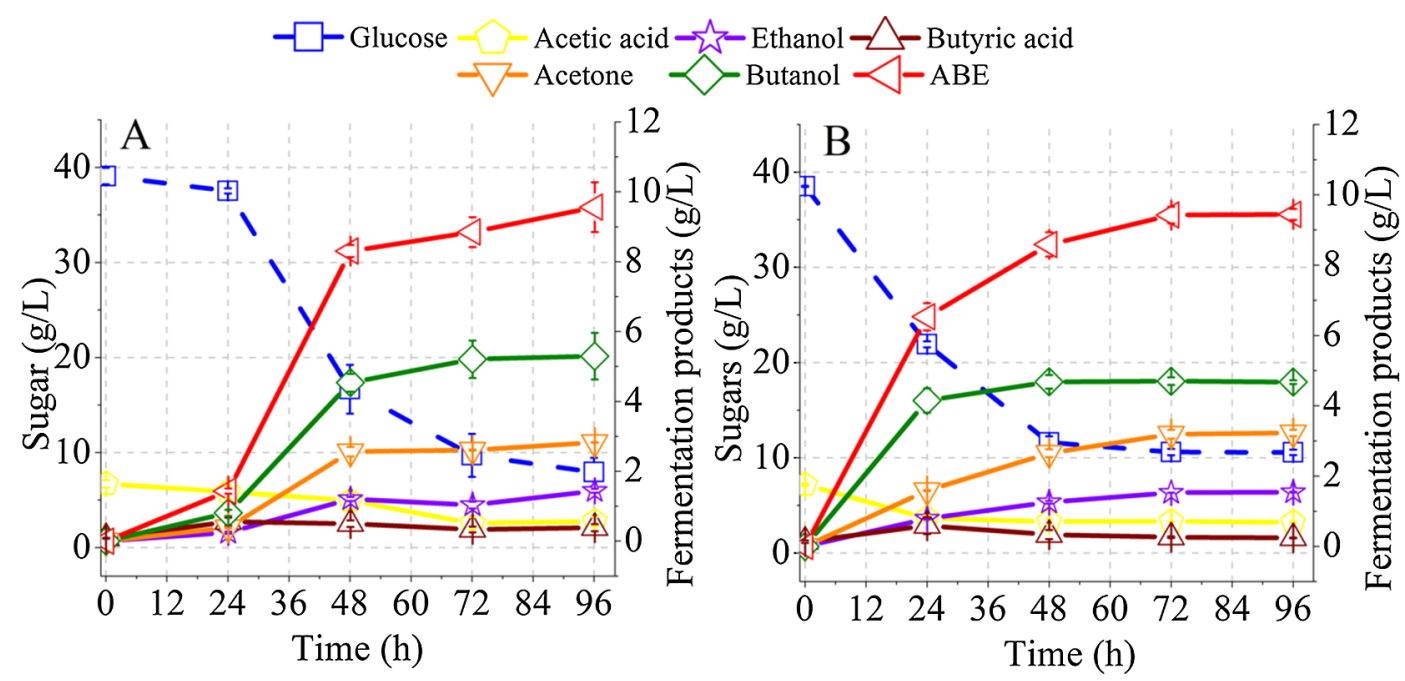

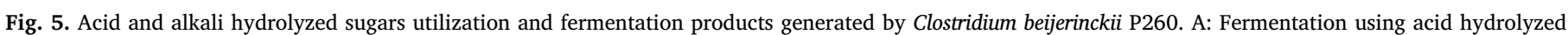
sugars (ACHS) as the substrate; B: fermentation using alkali hydrolyzed sugars (ALHS) as the substrate (fermentation completed at $72 \mathrm{~h}$ ).

Table 2

Degradation products in pretreated liquid and enzymatic hydrolysis liquid.

\begin{tabular}{|c|c|c|c|c|}
\hline \multirow[t]{2}{*}{ Degradation products $(\mathrm{g} / \mathrm{L})$} & \multicolumn{2}{|c|}{ Acid pretreatment ( $1 \%$ sulfuric acid, $60 \mathrm{~min})$} & \multicolumn{2}{|c|}{ Alkali pretreatment ( $2 \%$ sodium hydroxide, $30 \mathrm{~min}$ ) } \\
\hline & After pretreatment & After hydrolysis & After pretreatment & After hydrolysis \\
\hline Acetic acid & $0.4 \pm 0.06$ & $1.8 \pm 0.1$ & $0.6 \pm 0.03$ & $1.3 \pm 0.08$ \\
\hline HMF & $0.8 \pm 0.007$ & $0.02 \pm 0.0004$ & $0.005 \pm 0.0001$ & $0.003 \pm 0.0001$ \\
\hline Furfural & $0.04 \pm 0.005$ & $0.002 \pm 0.0001$ & $0.002 \pm 0.0002$ & $0.002 \pm 0.00001$ \\
\hline Total phenolic compounds & $1.5 \pm 0.05$ & $0.4 \pm 0.02$ & $1.8 \pm 0.1$ & $0.3 \pm 0.02$ \\
\hline
\end{tabular}

Data are expressed as mean \pm SD.

portion of ACHS or ALHS obtained from apple pomace, 4.5 or 4.7 portions of WSS could be generated from apple pomace simultaneously. Therefore, to make a full utilization of apple pomace sugars, we combined 4.5 portions of WSS with 1 portion of ACHS, and 4.7 portions of WSS with 1 portion of ALHS as the ABE fermentation medium, respectively. A control (glucose) with a similar amount of total sugars as WSS, WSS + ACHS, and WSS + ALHS was also conducted to test the performance of $C$. beijerinckii P260.

The results of sugars (fructose, glucose, and sucrose) utilization and fermentation products (acetone, butanol, ethanol, acetic acid, and butyric acid) generation using control, WSS, WSS + ACHS, and WSS + ALHS are shown in Fig. 4. Prior to the initiation of ABE fermentation, 29.3, 30.6, 32.1, and $30.1 \mathrm{~g} / \mathrm{L}$ total sugars were present in the control, WSS, WSS + ACHS, and WSS + ALHS substrates, respectively. These sugars were consumed at the end of $48 \mathrm{~h}$ fermentation (Fig. 4A-D); therefore, we stopped fermentation at $48 \mathrm{~h}$. Compared with control, sugars in apple pomace substrates were depleted faster. At $24 \mathrm{~h}$, sugars in WSS, WSS + ACHS, WSS + ALHS were almost used up, while about $6.7 \mathrm{~g} / \mathrm{L}$ glucose still remained in the control substrate. One of the possible reason is that some nutrients such as vitamins or minerals in apple pomace may stimulate the sugar consumption by $C$. beijerinckii P260 [32]. From 24 to $48 \mathrm{~h}$, a slight increase of ABE production was found in WSS, WSS + ACHS, and WSS + ALHS (Fig. 4F-H), which was attributed to the utilization of residual monomer sugars such as glucose, sucrose, xylose, galactose, and fructose (about $0.1-0.2 \mathrm{~g} / \mathrm{L}$ ) and might also be due to the utilization of some water extractable polysaccharides such as starch [33,34]. At last, a total of $11.5,10.1,10.7$, and $10.8 \mathrm{~g} / \mathrm{L} \mathrm{ABE}$ were produced from control, WSS, WSS + ACHS, and WSS + ALHS, respectively. The concentrations of butanol in control, WSS, WSS + ACHS, and WSS + ALHS were $8.0,7.5,7.1$, and $7.1 \mathrm{~g} / \mathrm{L}$, respectively (Fig. 4E-H). The mechanism behind the lower ABE yield in apple pomace substrates compared with control is currently unclear. However, from the application perspective, applying apple pomace waste material as the fermentation substrate could solve the apple pomace waste management problem to a certain extent, and in the meantime, benefit the environment.

ABE fermentation was also conducted using $100 \%$ ACHS or ALHS as a substrate, respectively. Only the utilization of glucose is shown in Fig. 5 since the concentration of the sum of other sugars including sucrose, xylose, galactose, and fructose is less than $2.5 \mathrm{~g} / \mathrm{L}$. The results showed that fermentation using ACHS or ALHS resulted in a longer fermentation time, and thus a lower fermentation rate, compared with fermentation using WSS, WSS + ACHS, and WSS + ALHS as substrates. When ALHS was used as a fermentation medium, the fermentation was not completed until $72 \mathrm{~h}$ with an ABE productivity of $0.13 \mathrm{~g} / \mathrm{L} / \mathrm{h}$. When ACHS was used as the fermentation medium, the ABE productivity was even lower than the ALHS fermentation. Only $1.6 \mathrm{~g} / \mathrm{L}$ of glucose was consumed during the first $24 \mathrm{~h}$, and the fermentation was not completed until $96 \mathrm{~h}$, with an ABE productivity of $0.10 \mathrm{~g} / \mathrm{L} / \mathrm{h}$. This low fermentation rate might be due to the generated inhibitors that inhibit fermentation [31]. As can be seen in Table 2, the contents of degradation products (inhibitors) including HMF and furfural are significantly $(p<0.05)$ higher in liquids after acid pretreatment and hydrolysis than those in liquids after alkali pretreatment and hydrolysis. A previous study found that the apple pomace hydrolysate obtained after nitric acid pretreatment and enzymatic hydrolysis was not fermentable and the possible reason was the high content of inhibitors generated in the acidic treatment [13]. At last, a total of 9.6 and $9.4 \mathrm{~g} / \mathrm{L}$ of $\mathrm{ABE}$ were generated by consumption of 30.4 and $28.0 \mathrm{~g} / \mathrm{L}$ of total sugars from ACHS and ALHS, respectively. Overall, the result indicates that the generated inhibitors from the pretreatments could negatively affect the ABE fermentation rate and titers; however, this negative effect could be alleviated by mixing the hydrolyzed sugars with water 


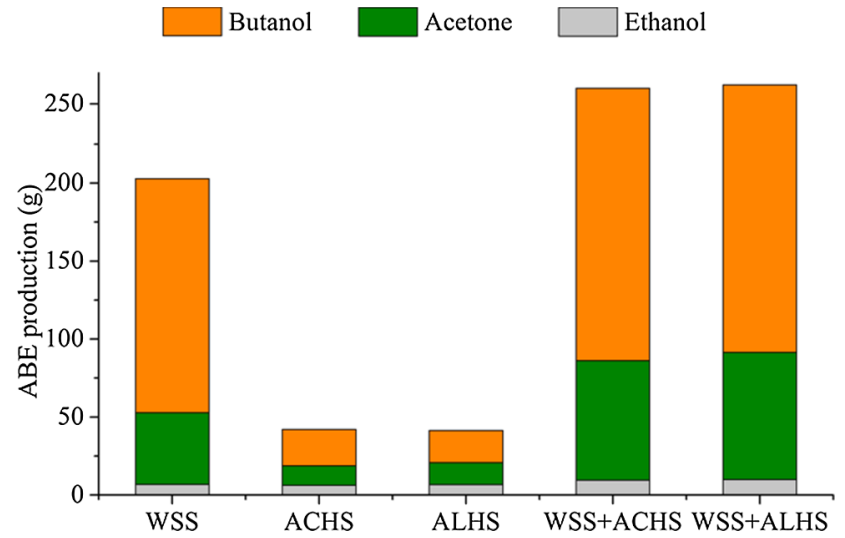

Fig. 6. Overall ABE production from each kg of dry apple pomace based on the mass balance.

soluble sugars. This clearly shows the advantage of the proposed process of using both water soluble and hydrolyzed sugars by combining them together as the fermentation substrate.

To see if the results of current ABE fermentation from apple pomace are comparable with previous studies, a detailed comparison is shown in Table 3. As can be seen from this table, ABE production, solvent yield, and $A B E$ productivity are similar to those reported in other references using apple pomace soluble sugars or structural carbohydrates as the substrates.

Finally, the overall ABE production from apple pomace was calculated based on the mass balance. Fig. 6 shows the overall ABE production from the fermentation of each $\mathrm{kg}$ of dry apple pomace using different substrates including WSS, ACHS, ALHS, WSS + ACHS, and WSS + ALHS. By fermenting WSS, about $202.8 \mathrm{~g} \mathrm{ABE}$ including $46.0 \mathrm{~g}$ acetone, $150.0 \mathrm{~g}$ butanol, and $6.8 \mathrm{~g}$ ethanol could be generated. By fermenting only ACHS or ALHS, about 42.1 or $41.4 \mathrm{~g}$ ABE including 12.5 or $14.0 \mathrm{~g}$ acetone, 23.3 or $20.7 \mathrm{~g}$ butanol, and 6.3 or $6.7 \mathrm{~g}$ ethanol could be generated, respectively. However, by the combination of about $20 \%$ of acid or alkali hydrolyzed sugars with WSS, significantly $(p<0.05)$ higher amount of ABE could be generated. For the WSS + ACHS substrate, a total of $260.1 \mathrm{~g} \mathrm{ABE} \mathrm{(76.6} \mathrm{g} \mathrm{acetone,} 174.0 \mathrm{~g}$ butanol, and $9.5 \mathrm{~g}$ ethanol) was obtained from each $\mathrm{kg}$ of dry apple pomace. As to WSS + ALHS, a total of $262.2 \mathrm{~g} \mathrm{ABE}$ (81.6 g acetone, $170.7 \mathrm{~g}$ butanol, and $9.9 \mathrm{~g}$ ethanol) can be generated from each $\mathrm{kg}$ of dry apple pomace.

From the economic perspective, the comprehensive utilization of both water soluble and hydrolyzed sugars from apple pomace provides several benefits. First, the proposed process will lead to an increase of ABE yield from $203 \mathrm{~kg}$ (WSS) to $262 \mathrm{~kg}$ (WSS + ALHS) from each tonne of apple pomace (Fig. 6), Considering the current market price of butanol $(\$ 1.2 / \mathrm{kg})$, acetone $(\$ 0.9 / \mathrm{kg})$, and ethanol $(\$ 0.5 / \mathrm{kg})[35]$, the potential economic value of the increased yield of ABE is about $\$ 58$ for processing each tonne of apple pomace (DW), which could contribute significantly to the economic performance of the process, e.g., internal rate of return. Second, by mixing water soluble sugars with the hydrolyzed sugars, we found that the negative effect of inhibitors in the hydrolyzed sugar substrate was mitigated in ABE fermentation. This could potentially reduce the operating and capital costs of the butanol production by eliminating the expensive detoxification step. Usually the overliming process is used to detoxify the pretreated biomass; however, this process results in a significant amount of sugar lost $(\sim 13 \%)$ due to side reactions occurring at high $\mathrm{pH}$ and has a high capital cost [36]. Third, the conversion of water soluble and hydrolyzed sugars to butanol could share the same equipment (e.g., fermenters, distillation columns), which would further reduce the capital cost per unit of butanol production. On the other hand, compared with only using water soluble sugars, more unit operations such as pretreatments and enzymatic 
hydrolysis are needed for using both the water soluble and hydrolyzed sugars. Therefore, a detailed techno-economic analysis is warranted in the future to evaluate the economic feasibility of this designed process.

In the present study, we find that there is still a potential to further increase the production of total ABE. One way is to increase the solid to liquid ratio in the soluble sugar extraction, and thus can increase the sugar concentration in the fermentation medium. In addition, in-situ solvent recovery technologies such as vacuum stripping and pervaporation membranes can be integrated to the fermentation system to selectively recover ABE from the fermentation broth $[11,37,38]$.

\section{Conclusion}

In this study, an integrated process aiming at a comprehensive utilization of both apple pomace soluble sugars and acid or alkali hydrolyzed sugars to produce ABE by anaerobic fermentation was proposed. All substrates including WSS, ACHS, ALHS, WSS + ACHS, and WSS + ALHS were fermentable by $C$. beijerinckii. The fermentation using ACHS as the substrate had the lowest productivity which was probably due to the highest degradation products such as HMF and furfural that inhibited fermentation. The fermentations using WSS, WSS + ACHS, or WSS + ALHS resulted in higher productivities and final $\mathrm{ABE}$ concentrations than the fermentations using ACHS or ALHS. Based on the mass balance, 42.1, 41.4, 202.8, 260.1, and 262.2 $\mathrm{g}$ of ABE were produced from each $\mathrm{kg}$ of dry apple pomace using ACHS, ALHS, WSS, WSS + ACHS, and WSS + ALHS as the fermentation substrates, respectively. This result showed the superiority of the combination of water soluble sugars and hydrolyzed sugars in apple pomace for ABE production. The designed process in this study can be adapted and applied to other food processing byproducts or wastes, such as white grape pomace, citrus wastes, and pineapple peels.

\section{Acknowledgments}

This work was supported by the USDA AFRI Foundational Program (grant number 2018-67021-27895) and the Virginia Agriculture Experiment Station and the Hatch Program of the National Institute of Food and Agriculture (NIFA), USDA.

Mention of trade names or commercial products in this article is solely for the purpose of providing scientific information and does not imply recommendation or endorsement by the United States Department of Agriculture. USDA is an equal opportunity provider and employer.

\section{References}

[1] Cargnin ST, Gnoatto SB. Ursolic acid from apple pomace and traditional plants: a valuable triterpenoid with functional properties. Food Chem 2017;220:477-89.

[2] Yates M, Gomez MR, Martin-Luengo MA, Ibañez VZ, Serrano AMM. Multivalorization of apple pomace towards materials and chemicals. Waste to wealth. J Clean Prod 2017;143:847-53.

[3] Magyar M, da Costa Sousa L, Jin M, Sarks C, Balan V. Conversion of apple pomace waste to ethanol at industrial relevant conditions. Appl Microbiol Biotechnol 2016;100:7349-58.

[4] Vendruscolo F, Albuquerque PM, Streit F, Esposito E, Ninow JL. Apple pomace: a versatile substrate for biotechnological applications. Crit Rev Biotechnol 2008;28:1-12.

[5] Jin Q, Yang L, Poe N, Huang H. Integrated processing of plant-derived waste to produce value-added products based on the biorefinery concept. Trends Food Sci Technol 2018;74:119-31.

[6] Bhushan S, Kalia K, Sharma M, Singh B, Ahuja PS. Processing of apple pomace for bioactive molecules. Crit Rev Biotechnol 2008;28:285-96.

[7] n-Butanol market analysis, application analysis, regional outlook, competitive strategies and forecasts, 2015 to 2022. Available at: https://www. grandviewresearch.com/industry-analysis/n-butanol-market [accessed 18.06. 2018].

[8] Qureshi N, Ezeji TC. Butanol, 'a superior biofuel'production from agricultural residues (renewable biomass): recent progress in technology. Biofuels Bioprod Biorefin 2008;2:319-30.
[9] Mahapatra MK, Kumar A. A short review on biobutanol, a second generation biofuel production from lignocellulosic biomass. J Clean Energy Technol 2017;5:27-30.

[10] Salehi Jouzani G, Taherzadeh MJ. Advances in consolidated bioprocessing systems for bioethanol and butanol production from biomass: a comprehensive review. Biofuel Res J 2015;2:152-95.

[11] Huang H, Qureshi N, Chen MH, Liu W, Singh V. Ethanol production from food waste at high solids content with vacuum recovery technology. J Agric Food Chem 2015;63:2760-6.

[12] Voget C, Mignone C, Ertola R. Butanol production from apple pomace. Biotechnol Lett 1985;7:43-6.

[13] Hijosa-Valsero M, Paniagua-García AI, Díez-Antolínez R. Biobutanol production from apple pomace: the importance of pretreatment methods on the fermentability of lignocellulosic agro-food wastes. Appl Microbiol Biotechnol 2017;101:8041-52.

[14] Ballesteros I, Ballesteros M, Cara C, Sáez F, Castro E, Manzanares P, et al. Effect of water extraction on sugars recovery from steam exploded olive tree pruning. Bioresour Technol 2011;102:6611-6.

[15] Rodríguez-Sevilla MD, Villanueva-Suárez MJ, Redondo-Cuenca A. Effects of processing conditions on soluble sugars content of carrot, beetroot and turnip. Food Chem 1999;66:81-5.

[16] Parmar I, Rupasinghe HV. Bio-conversion of apple pomace into ethanol and acetic acid: enzymatic hydrolysis and fermentation. Bioresour Technol 2013;130:613-20.

[17] Ezeji T, Qureshi N, Blaschek H. Acetone butanol ethanol (ABE) production from concentrated substrate: reduction in substrate inhibition by fed-batch technique and product inhibition by gas stripping. Appl Microbiol Biotechnol 2004;63:653-8.

[18] Bravo L, Saura-Calixto F. Characterization of dietary fiber and the in vitro indigestible fraction of grape pomace. Am J Enol Vitic 1998;49:135-41.

[19] David T, Tina E. Determination of acid-insoluble lignin in biomass. Laboratory Analytical Procedure, LAP-003. Golden, CO: National Renewable Energy Laboratory; 1992.

[20] Raymond R, Tina E. Determination of carbohydrates in biomass by high performance liquid chromatography. Laboratory Analytical Procedure, LAP-002. Golden, CO: National Renewable Energy Laboratory; 1996.

[21] Tina E. Determination of acid-soluble lignin in biomass. Laboratory Analytical Procedure, LAP-004. Golden, CO: National Renewable Energy Laboratory; 1992.

[22] Tina E. Standard method for the determination of extractives in biomass. Laboratory Analytical Procedure, LAP-010. Golden, CO: National Renewable Energy Laboratory; 1994.

[23] Gouw VP, Jung J, Zhao Y. Functional properties, bioactive compounds, and in vitro gastrointestinal digestion study of dried fruit pomace powders as functional food ingredients. LWT-Food Sci Technol 2017;80:136-44.

[24] Spanos GA, Wrolstad RE. Influence of processing and storage on the phenolic composition of Thompson seedless grape juice. J Agric Food Chem 1990;38:1565-71.

[25] Kennedy M, List D, Lu Y, Foo LY, Newman RH, Sims IM. Apple pomace and products derived from apple pomace: uses, composition and analysis. In: Linskens HF, Jackson JF, editors. Analysis of plant waste materials. Modern methods of plant analysis. Berlin, Heidelberg: Springer; 1999. p. 75-119.

[26] Hours R, Voget C, Ertola R. Apple pomace as raw material for pectinases production in solid state culture. Biol Wastes 1988;23:221-8.

[27] Wang H, Thomas R. Direct use of apple pomace in bakery products. J Food Sci 1989;54:618-20.

[28] Dreyer J, Van Der Walt W. Evaluation of apple pomace as a bulking agent. S Afr J Sci 1979;75:124-6.

[29] Ngadi M, Correia L. Solid state ethanol fermentation of apple pomace as affected by moisture and bioreactor mixing speed. J Food Sci 1992;57:667-70.

[30] Mood SH, Golfeshan AH, Tabatabaei M, Jouzani GS, Najafi GH, Gholami M, et al Lignocellulosic biomass to bioethanol, a comprehensive review with a focus on pretreatment. Renew Sustain Energy Rev 2013;27:77-93.

[31] Alvira P, Tomás-Pejó E, Ballesteros M, Negro M. Pretreatment technologies for an efficient bioethanol production process based on enzymatic hydrolysis: a review. Bioresour Technol 2010;101:4851-61.

[32] Qureshi N, Lai L, Blaschek H. Scale-up of a high productivity continuous biofilm reactor to produce butanol by adsorbed cells of Clostridium beijerinckii. Food Bioprod Process 2004;82:164-73.

[33] Stevenson DG, Domoto PA, J-1 Jane. Structures and functional properties of apple (Malus domestica Borkh) fruit starch. Carbohydr Polym 2006;63:432-41.

[34] Ezeji T, Qureshi N, Blaschek H. Continuous butanol fermentation and feed starch retrogradation: butanol fermentation sustainability using Clostridium beijerinckii BA101. J Biotechnol 2005;115:179-87.

[35] ICIS. Commodities prices, markets and analysis. https://www.icis.com/explore/ commodities/?intcmp = mega-menu-explore-commodities; 2019 [assessed 25.01 . 2019].

[36] Humbird D, Davis R, Tao L, Kinchin C, Hsu D, Aden A, et al. Process design and economics for biochemical conversion of lignocellulosic biomass to ethanol: diluteacid pretreatment and enzymatic hydrolysis of corn stover. Golden: National Renewable Energy Lab; 2011.

[37] Huang H, Singh V, Qureshi N. Butanol production from food waste: a novel process for producing sustainable energy and reducing environmental pollution. Biotechnol Biofuels 2015;8:147-59.

[38] Qureshi N, Meagher M, Huang J, Hutkins R. Acetone butanol ethanol (ABE) recovery by pervaporation using silicalite-silicone composite membrane from fedbatch reactor of Clostridium acetobutylicum. J Membr Sci 2001;187:93-102. 